\title{
Transitional Writing and "Third Space" Learning: Professional Writing Students and the Work Experience
}

\section{Diana Wegner}

\begin{abstract}
This paper is based on a long-term study of professional writing students in an internship, "work experience" course. Building upon work theorizing the problematic gap between classroom instruction and workplace practice, this study extends analysis to explore the role of transitional pedagogy in the learning dynamics that populate the "space between" the classroom and the workplace. It shows how students use both their acquired strategic resourcefulness and tools such as transitionally located scaffolding structures to facilitate workplace participation. The analysis is framed largely by learning community theory and activity theory, with emphasis on the concepts of developmental transfer and consequential transition, which prove productive for elucidating the nature of transformative learning and for assessing the effects of transitional pedagogy. I examine both conventional on-site work placements and the additional challenges that off-site internships present. The evidence here suggests that an effective transitional writing pedagogy should aim to create a transitional community of practice, a "back region" or "third space" where students and mentors can problemsolve and share resources. Findings support recent elaborations of activity theory in contexts of transitional learning and educational reform, and reinforce the need to strengthen weak links in school-employer work experience collaborations.
\end{abstract}

\section{Key words \\ internship, learning community, activity theory, developmental transfer}

\section{Résumé}

Cet article se base sur une étude à long terme d'étudiants en écriture professionnelle inscrits à un cours comportant des éléments d'internat et d'expérience de travail. Cette étude se fonde en outre sur des œuvres traitant de l'écart problématique entre l'instruction en classe et la pratique au travail afin d'explorer le rôle de la pédagogie transitionnelle dans les dynamiques d'apprentissage " occupant l'espace » entre la salle de classe et le lieu de travail. Elle montre comment les étudiants utilisent à la fois les ressources stratégiques qu'ils ont acquises et des outils tels que les structures d'étayage afin de mieux s'intégrer au monde du travail. Cette analyse se fonde en grande partie sur la théorie des communautés d'apprentis et celle de l'activité. Elle met l'accent sur les concepts de " transfert des apprentissages » et de " transition subséquente ». Ceux-ci s'avèrent utiles pour élucider ce qu'est l'apprentissage transformatif et pour évaluer les effets de la pédagogie transformative. J'examine à la fois les placements de travail sur place et les défis supplémentaires que représentent les internats hors site. Les résultats de cet examen suggèrent qu'une pédagogie transitionnelle axée sur l'écriture devrait viser à créer une communauté de praticiens transitionnelle, un « troisième espace » pour ainsi dire entre école et travail permettant aux enseignants et aux étudiants de partager leurs connaissances et de s'entraîner sur la résolution de problèmes. Les données recueillies secondent l'élaboration récente de 
la théorie de l'activité pour l'apprentissage transitionnel et la réforme en éducation, tout en renforçant le besoin d'encourager les collaborations entre pédagogues et employeurs par rapport à l'expérience de travail.

\section{Mots clés \\ internat, communauté d'apprentis, théorie de l'activité, transfert des apprentissages}

It is now widely embraced that effective workplace writing instruction depends on pedagogical strategies that move beyond case study approaches and provide authentic contexts for students' writing tasks (Dias et al., 1999; Gee, 1996; Pare, 2000). This facilitation entails not only arranging opportunities for students to write in professional contexts, but also building in adequate transitional supports to help students negotiate the terrain of unfamiliar organizations. For the transitional writing student, "a key criterion of success ... relates to the degree to which the learner sees the task as authentic-that is, one that has consequences in context" (Dias et al., 1999, p. 189), but this sense of authenticity comes about only through the privilege of participation and a self-reflexive sense of consequential learning. Organizations limit such participation, partly through their practices of membership, and partly through everyday constraints, such as workload, that may reduce participation and learning opportunities. The absence of support can be additionally challenging for those who are assigned by employers to work at home and who are therefore further marginalized from the workplace culture and opportunities for participation.

While research on transitional learning has tended to focus on apprentice-writers in academic disciplines (Berkenkotter \& Huckin, 1995; Berkenkotter, Huckin, \& Ackermann, 1991; Giltrow \& Valiquette, 1994), there now exists a number of workplaceoriented studies, with a notable cluster of key papers in the 1990s that created an initial framework for research. These papers investigated the differences between workplace and classroom writing acquisition (Dias et al., 1999; Freedman and Adam, 1996; Freedman, Adam, \& Smart, 1994), transitional writing students in work experiences or "internships" (Anson \& Forsberg, 1990; Ketter \& Hunter, 2004; Ledwell Brown, 2000; Lingard \& Haber, 2002; Lutz, 1989; Smart \& Brown, 2002), and writing students completing client-based projects (Blakeslee, 2001; Kastman Breuch, 2001; Smart \& Brown, 2002; Wickliff, 1997). The findings of these studies indicate that transitional writing students not only experience conflicts between workplace and classroom practices, but they also face the challenge of gaining access to organizational knowledge and tools, resources that are critical to successful apprenticeships. As Lave and Wenger (1991) have shown, apprentice writers must have this access in order to achieve "legitimate peripheral participation" in an organization.

While these studies have taught us much about the barriers to participation and the strategies that writing students utilize for access--both their misguided efforts and their successes in the workplace - rarely do they explicitly analyze the dynamics of learning as they unfold in the "space between" the classroom and the workplace. Studies of scaffolding support for transitional writers are usually situated in the 
classroom, as in Burnette's (1993) use of collaboration, Anson and Forsberg's (1990) use of teacher-led group discussions, and Smart and Brown's (2002) weekly seminar led by two instructors. Similarly, as an object of analysis, the role of transitional scaffolding is usually treated as transparent. In studies of student writers using transitional scaffolding outside the classroom, such as the class e-mail list serve in Smart and Brown's study, such scaffolding is referred to in general terms as a vehicle for providing "support" from peers and instructors (p. 122), and seems to be valued primarily as a research source of information on 'interns' own perspectives on their workplace experiences" (p. 121). Moreover, these supportive activities are teacher-led and, to a greater or lesser extent, they are teacher-evaluated for effectiveness. Compared to what we know about students' classroom performances and the effectiveness of classroom-based learning, how effectively writing students negotiate transitional contexts in their learning is largely unknown, and the use of scaffolding techniques is still relatively unevaluated.

One exception is Wilson et al.'s (2005) study of collaborative work teams made up of students, instructors, and organizational practitioners. They present their study as a response to Hunt's (2001b) critique of Dias et al.'s (1999) Worlds Apart and his urging to switch the emphasis away from the gap between workplace and classroom and on to efforts to bridge the two, even as they "collide": "These worlds are certainly apart-no question about that-but it strikes me it might make more sense to connect them than to talk about better ways of jumping from one to the other" (p. 146). Hunt (2001a) elaborates elsewhere that researchers should not assume "that there's nothing out there in the space between the worlds" and he implies that work needs to be done researching this transitional space. In his response to Hunt's critique, Dias (2001) supports the need to create "arrangements" that "go some way toward realizing the far richer communicative relations that contextualize writing in the workplace [compared to the classroom]" and specifically refers to the strategy of "constituting the class as a working group" outside the conventional classroom setting. This is the scaffolding strategy Wilson et al. adopt for their graduate class.

This collaborative strategy finds a theoretical home in the broader work of TuomiGrohn and Yrjo Engestrom (2003), whose collection of studies of "developmental learning" spans a number of both transitional vocational contexts and fully professional settings. Their concept of collaboration is extended to include employers, practitioners, teachers and students in transitional learning, and is proposed as a basis for educational reform in transitional pedagogy, which currently often leaves students stranded as interns. They argue that this collaborative approach is necessary to help students realize genuine learning transfer or "developmental transfer" "at or around boundaries of multiple activity systems" (p. 30)--the workplace, school, and other subcultural and professional activity systems, which can overlap in productive ways with each other in transitional contexts. Following this direction, this study explores how transitional writing students strategize for organizational access, how they apply their resourcefulness, and how they use tools such as the collaborative transitional scaffolding of a web forum.

The goals of this study are formulated as the following questions: 1) What barriers to participation and learning do student writers encounter in their work experiences? 2) What learning strategies and use of tools, such as the web forum, do 
they marshall toward achieving workplace access and participation? I examine these questions in both on-site and off-site work experience contexts, and conclude with implications for transitional writing theory and pedagogy. The findings indicate that, on the one hand, as students are membershipped into organizations to varying degrees, frequently their marginal status is difficult to overcome-a difficulty that is more acutely experienced in off-site contexts. On the other hand, students apply their own resourcefulness, often in concert with available transitional scaffolding, to help negotiate these barriers and to achieve meaningful participation in organizations. In some cases, their self-descriptions indicate successful performance but not necessarily learning transfer; in others, there is strong evidence of genuine learning transfer and grounds for designing transitional supports that aim for developmental transfer. Findings focus less on workplace performance, as in typical performance evaluations, but are based on evidence of learning transfer and "consequential transition" (Beach, 2003) drawn from the "back regions" (Goffman, 1959) - that third space between classroom and workplace where students are not under pressure to perform for evaluation, where their concerns, problems, and anxieties can be expressed "off-the-record." This is both concurrent with and preparatory for workplace and classroom performance, a rehearsal and trouble-shooting space, neither in the workplace, nor in the classroom. It has neither the visibility nor the consequences of a performing working group, yet it bolsters that performance by transforming the "space between" into a third productive "working space" (Wilson et al., 2005, p. 40).

In what follows, I sketch the concept of transitional space as a site where multiple learning communities can interact as a dialogical zone of proximal development (Vygotsky, 1978; Wenger, 1998; Wertsch, 1991). It includes both front and back regions of activity, where participants can share tools, problem-solve, and reflect. This section is followed by a description of the methodology of this study, the larger context of the professional writing program, its transitional learning pedagogy, and the work experience course. Findings are then presented and discussed, and are followed by a closing section on implications for the development of transitional writing pedagogy.

\section{Learning Communities, Developmental Transfer, and "Back Region" Rehearsal}

The analysis of transitional learning is grounded in recent developments in activity theory, models of learning communities (communities of practice), and learning transfer theory. Specifically, the theoretical framework is based on reconceptualizations of Vygotskyan (1978) activity system theory and Bakhtinian (1981) dialogism in theories of situated learning (Dias et al., 1999; Lave \& Wenger, 1991; Wenger, 1998) and learning transfer (Engestrom, 1999, 1995; Tuomi-Grohn \& Engestrom, 2003; Wertsch, 1991). Within this framework I have incorporated Goffman's (1959) concept of "back region" rehearsal.

In their work on activity systems and learning transfer, Tuomi-Grohn and Engestrom (2003) have incorporated and elaborated Wenger's use of the concept of boundary crossing and Star and Griesemer's (1989) concept of boundary objects (pp. 392-393). Tuomi-Grohn and Engestrom propose that effective learning transfer can occur only through a dynamic, collaborative process, involving the multiple cognitions of actors or participants, the sharing of tools as boundary-objects, and overlapping activity systems. In this dynamic learning context, learning and teaching are conscious 
motivations in themselves. Students draw upon a range of resources (cognitions and tools) to create their own boundary-objects and to problem-solve. Boundary objects "inhabit several intersecting social worlds ... and satisfy the ... requirements of each of them," thereby "manag[ing] both diversity and cooperation" (Star \& Griesemer, 1989, p. 393). As this study will show, boundary objects can include software programs, drafts, comment sheets, company brochures, meetings, phone conversations, and even the "track changes" function in revision.

Students succeed in learning when they deploy a developmental resourcefulness that enables them to recognize and capitalize on these diverse resources: they shift goals, change strategy, and, as needed, take up one tool and drop another. Such learning is attuned to multiple perspectives simultaneously. It is "a multidimensional space" where students are responding "simultaneously" to more than one community (Hudson, 1980, pp. 142-143). Optimally, such learning is both self-reflective and product-oriented, and depends on temporary combinations of contextual elements that disappear as the overlappings of different activity systems change from moment to moment. Learning situations are thus characterized by polycontextuality, boundarycrossing, and mutually recognizable boundary objects shared across activity systems (Engestrom, 1995).

In this third space of multiple activity systems, transitional pedagogy aims to provide the conditions of possibility for the development of a zone of proximal development: the space between "actual development," measured by competence in individual problem-solving, and "potential development," measured by competence in collaborative problem-solving with mentors or peers (Vygotsky, 1978, p. 86). Such transitional pedagogy fosters this third dimension through an overlapping of workplace and school spaces, actors, tools, and other resources. From activity system theory and the concept of distributed learning, we can assume that, in a learning community, a zone of proximal development can be fostered with supports for cycles of activity and the productive distribution of cognition among peers from different organizational contexts. This constructed zone enables students to move from their actual to their potential level development. Vygotsky describes this development as "'good' learning ... which is in advance of development,' but "lags behind ... learning processes" themselves (pp. 89-90). In other words, in the zone of proximal development, learners' reach exceeds their grasp. This zone would ideally offer two important conditions for learning: (1) a context for bringing both classroom and workplace learning into a shared space, so that they may interact productively, and (2) an experiential dimension that leads to learning transfer (Wenger, 1998, pp. 67-68). It would transcend dichotomies of theory versus practice through the facilitation and deployment of techne, which involves both the use of epistemic knowledge or theory, which is knowledge that is shared and reproduced as a tool or artefact, and tacit experiential knowledge acquired through authentic participation (Gordon, 2002).

Effective transitional pedagogy can foster the creation of a dynamic staging area for transforming knowledge and acquiring skills in professional contexts. The effective design of pedagogical scaffolding in transitional spaces should aim to transform the gap between school and workplace into a productive juncture of the two as a working space anterior to the workplace and classroom. It should help create the conditions for "legitimate peripheral participation" (Dias et al., 1999; Lave \& Wenger, 1991) within the 
transitional space, where contact between participants--employers, practitioners, instructors, and newcomers--will both generate problems and facilitate problem-solving.

Tuomi-Grohn, Engestrom, and Young (2003) propose the concept of "developmental transfer" to describe the type of learning that is optimal in the zone of proximal development. This "process is multi-directional and multi-faceted, involving transitions between activity systems like school and workplace" (p. 4). However, the learner's agency is not "a mysterious entity"; rather "different individuals and groups ... take and leave the subject position" of a variety of roles offered by these overlapping activity systems (Tuomi-Grohn \& Engestrom, 2003, p. 30). In the process of these exchanges, tools, models, and practices are themselves "transformed and renegotiated" (p. 32). Beach (2003) argues that developmental transfer also involves "consequential transition" (p. 42): as the learner generalizes knowledge across the boundaries of activity systems, reflects and struggles with this new knowledge, "the individual's sense of self or social position" shifts (p. 42). Within the learner, identity and knowledge propagation are yoked in a kind of "developmental coupling" (p. 47) that involves both learning work-related knowledge and learning "how to learn" (p. 55). In consequential transition and developmental transfer, Beach further argues, it is critically important to foster those perturbations, disruptions, and disorientations of learning which are often elided as problematic in traditional educational settings, where continuity is valued and unprogrammatic anomalies are not (p. 57).

Since a certain dissonance of identity and disorientation is both inevitable and desirable, transitional learning spaces can be structured to provide a kind of home for this in situ problem-solving and rootlessness. Such a space can be constructed to facilitate a zone of proximal development in the "back regions" that exist at the boundaries of the classroom and the workplace. It can thus be an informal problemsolving, dialogical site of knowledge and strategy sharing. Unlike a front region, "the place where the performance is given" and judged by "certain standards" (Goffman, 1959 , p. 107), a back region is "a place, relative to a given performance," where the performer "can run through [the] performance .... relax ... step out of character" (p. 112). While Goffman (1959) advises that this back region "be kept closed to members of the audience" in order to "conceal" the "mistakes that were first made" (pp. 113-114), in transitional learning it is desirable to invite members of an otherwise evaluative audience-practitioners, employers and instructors - to participate as mentors. In this study, I have followed transitional students, as apprentice-writers, into the back regions of learning where peers, instructors, and employers can be witnesses and coaches, literally and virtually, to students' transitional selves.

The following section describes the methodology adopted for this study. This is followed by a description of the program, students, and transitional pedagogy, and a discussion of the findings and implications of the study.

\section{Methodology}

Empirical research methods were employed to provide qualitative data on the types of problems that arise for transitional writers, and on their strategic use of one transitional scaffolding tool, a web form dedicated for work experience students. Data was also collected on the special challenges facing students completing their work experience off-site. The data was collected from a mix of sources over four iterations of 
the work experience course. Because the study was initiated right after the 2002 work experience ended, for the first iteration (2002) data collection began with a post-work experience, retrospective questionnaire, completed by six students in early 2003. Postings from the web forum for work experience students were collected for the second (2003, 30 students) and third (2004, 23 students) iterations. For the third iteration, in addition to web postings, data was collected from interviews with the work experience instructor, four work experience students and four employers. A fourth set of data was drawn from nine off-site work experience students between 2002 and 2008, with questions related specifically to issues facing off-site work experience students. Five of these students and three employers completed questionnaires and participated in follow-up interviews (2003), and three off-site work experience students, two in 2004 and one in 2001, completed retrospective questionnaires. Web forum postings made by these students were also included in the data. Supplemental data was drawn from interviews with one on-site and two off-site employers (2007), a small focus group of offsite work experience students (2007), web postings from the 2008 work experience (20 students, of whom three were off-site work experience students), and students' postwork experience reports for their instructor. Interviews were taped and transcribed.

Using a grounded theory approach, analysis began with "open coding," eventually yielding more refined, "emergent" categories and corresponding "propositions" or themes (Cresswell, 2007, pp. 64-65). Categories were initially hypothesized from the literature and adjusted as the data was collected and studied over the period from 2003 to 2009 . The analysis involved what Cresswell calls "the constant comparative method of data analysis": "a 'zigzag' process out to the field to gather information, into the office to analyze the data, back to the field to gather more information, into the office, and so forth" (p. 64). Early categories such as "requests for help, real world naivite, awareness of learning, unchallenging work," became the emergent categories that frame the results of the study: Barriers: Insufficient Client Direction, Marginality, and Limited Home Support; Strategies and Problem-Solving: Past Work Experience Reports, Web Forum Peer Support, Web Forum Instructor Support, Collaboration, Mentors and Friends, Virtual Sleuthing.

\section{Background: The Professional Writing Program and the Work Experience}

The professional writing program offers a two-year, five semester advanced diploma that combines the theory and practice of writing. 'Its graduates are professional writing generalists who find positions in technical writing, editing, publishing, marketing, communications, media, and public relations. By the time of their work experience, they are already immersed in the analysis and the production of both academic and nonacademic genres, an important dimension of preparation for the work experience (Ketter \& Hunter, 2004). Students have studied rhetorical genre analysis, document design, editing, interpersonal communication, research methods, public relations and collaborative writing. As Ketter and Hunter (2004) recommend, instruction offers students a foundation and support for transitional experiences: "opportunities to write in nonacademic contexts," discussion on "how these non-academic contexts frame writing activity" and on "how writing activity ... is a means of operating purposively in the world" (p. 25). 
The work experience course is taken between the first and second year and requires 180 hours of writing-related work with an employer who has been recruited to provide a work-site for a student. During and after the work experience, students receive feedback and are evaluated by both the course instructor, who makes at least one site visit, and the employer supervisor, who is given guidelines for criteria. Final evaluation is assigned as either Mastery or No Credit Granted.

The program has incorporated a number of pedagogical supports recommended in studies of transitional writers. The preparatory curriculum includes a client-based project that functions as a passageway to the workplace experience: students move from taking on the role of apprentice-consultants from the ground of the classroom to taking on the role of apprentice-writers within organizations. Additional preparation for the work experience entails attendance at forums for informal discussions of the work experience, and faculty assessments of students' workplace suitability. The instructor identifies potential employers for work experiences, posts positions, and coaches students in job search skills. Students are required to have a one-page contract signed and filed for their work-experience position and to keep track of their work-experience hours. At the end of their work experience they submit this record and a twenty page report.

Once the work experience begins, they attend two additional face-to-face forums. Extra-classroom scaffolding is provided through a web-based forum dedicated for work experience students. The instructor tells participants that they are "not just chatting," but that they are professionals for whom the chat room is their "company intranet for the summer." The website also provides work-experience materials (including additional job postings), a calendar of work-experience-related activities, work experience reports from former students, and a complete list of past work experience placements. These materials provide important community history for newcomers. Students must familiarize themselves with these resources and post a minimum of ten web forum entries.

According to the instructor, the practical goal of the course is to "end up with a substantial chunk [of time] in the workplace and hav[e] something to show for it. . . the main objective of the course is to give them that experience, and give them something they can put on a resume or incorporate in their portfolio." The quality of these products is contingent upon the degree of participation and developmental transfer that students achieve at their work-site.

In the following sections, I describe the barriers to workplace participation that students experienced and their strategic use of tools for learning, including the web forum and key boundary objects.

Findings: Barriers and Strategies

\section{Barriers}

Work experience students face barriers to access and participation that fall into the categories of insufficient client direction and feedback, marginality, and lack of support at home.

\section{- Insufficient Client Direction and Feedback}

Some work experience students reported varying degrees of reticence in terms of employer direction and feedback. Such students may be stuck in what Anson and Forsberg (1990) call the second of three stages of transition" (p. 208). In the first pre- 
internship stage, students often imagine an "idealized" version of their internship which leads to the second stage of "disorientation," often marked by "frustration," "a sense of failure," and even negative "evaluations" of the employer (p. 208). Such dissatisfaction and criticism of employer involvement is manifested in the following comments:

(1) My Supervisor's .... expectations and direction were not specific. The student and the mentor both need to know what is expected, in detail.

(2) My mentor could've better prepared herself. She didn't always know what to do with me, and the situation could've been more mutually beneficial if she planned a few projects for me to work on rather than going day by day.

(3) I worked alone ... and I was at the mercy of experts who were reluctant to spend time with an intern.

Some students were disturbed by delays in feedback:

(4) I was surprised to have nothing to do on a number of days while waiting for feedback: I had to generate my own work.

(5) I never had any confirmation that the article was received and no feedback about whether it was good or needed work. Some [articles] were published and others were not but no explanations were given as to how this was decided.

It may be that some employers simply do not believe or realize that students need this kind of support or that it is even their role to provide it. In a study of organizational expectations of writers, Ledwell-Brown (2002) speculates that "many managers may not know how to help writers learn to write"; it is also possible that their "primary goal may be to complete the job rather than to educate the writer" (p. 220).

\section{- Marginality}

Some students reported experiences that marked them as outsiders in their workplace cultures. For example, one student did not know that the staff at his employer organization (an educational institution) were unionized, and unwittingly acted inappropriately by crossing job classifications:

(6) In an emergency, I chaperoned students in a computer lab; this drew a grievance from a teaching assistant, in the unionized environment. ... Unhappiness reigned throughout the department, on my behalf.

As a result, this student was actually shunned at a subsequent meeting by a senior administrator. Other students registered a sense of being "invisible":

(7) My quietness resulted in [my supervisor] not noticing I was there, and me not getting the assistance or the questions I needed answers from her ... This "invisibility" extended to other employees as well; and I did not do enough to make my presence felt. 
(8) [l felt] detached, like a consultant. [Other staff] don`t know who we are.

Not surprisingly, off-site work experience students felt especially marginalized:

(9) I was an "outsider" with the organization throughout my work experience.

- Limited Support at Home

Off-site students working at home were often perceived by others as not really "working." One student was queried by friends about why her son was in day-care:

(10) People have a perception that since I'm working from home, I'm not really "working" and that my days are free to do what I want with them. It has been hard to have people understand that my son is in daycare because I have work I need to do that day.

Another student was told by his co-workers (at his second job) that it "sucks to go home and work." He said, "they see it as a burden," not as an opportunity to learn. He also experienced some pressure from his father who wanted him to help paint his house, since his son was "at home" and seemed to be available.

For the many students who do not have an active and present mentor, program scaffolding, in play with their own strategies to achieve participation, can widen and deepen the circle of learning and problem-solving. In the next section, I describe how students strategized in "the back regions" of their work experience to enhance their participation and performance. Data is drawn from web forum postings, student interviews, and student questionnaires.

\section{Strategy Sharing and Problem-Solving}

Students shared strategies and collaboratively problem-solved to address barriers to access and participation. This included reading former students' work experience reports and "off-the-record" postings to the web forum where they could share experiences and suggestions with peers, second-year students, the work experience instructor and other faculty who can "listen in" and respond if so requested. Other strategies involved collaboration, consulting mentors and friends, and virtual sleuthing of such features as "track changes." The findings indicate both the explicit sharing of successful strategies and interactive problem-solving.

\section{- Past Work Experience Reports}

Students read about others' strategies in past work experience reports posted at the work experience website. For example, a student wrote that he felt "under-utilized" and shared his solution of simply creating new work on his own:

(11) I wasn't sure that my employers had an accurate picture of what we as students could be expected to do. I felt very much as though I out ran their need for a writer. ... Instead of just going slack I tried to put my initiative to work by designing and submitting a company brochure. This was big jump for me. l'd never had ... the mandate to create my own projects before. It felt terrific! 
- Web Forum Peer Support

In another posting to the web forum, one student recommended to others a "wish list" strategy introduced by her supervisor to help her gain a wide variety of experience:

(12) $\ldots$ the Technical Writer that I am working under ... has come up with ... a pretty good idea for me to do for the halfway point of the practicum. She wants me to create a wish list of everything I would like to try ... that aren't a part of what l've done so far, ... I am posting this ... to give the rest of you this idea to suggest to your Supervisor if you think it will help you.

Another student shared her plan to use observation as a participation strategy:

(13) We put all our stories into Quark, but they won't let me near THAT computer. Next week I plan to sit down with the editor and watch him load the stories for a few hours.

In web forum exchanges, on-site students frequently engaged in interactive problem-solving, requesting and offering assistance. For example, one student asked about the common problem of feeling under-challenged in the work experience, a factor that can seriously limit participation:

(14) ... my problem is that they don't seem to have enough for me to do. ... I feel really bad asking ... when is it too much and you need to stop asking?

A classmate responded with advice to approach one's bosses:

(15) I had a similar issue at my work experience.... it was getting ridiculous, so I called a meeting with my bosses and explained ... I was concerned I wasn't using some of my skills and fulfilling the work term requirements. They were very receptive and said they needed me to remind them of these things because they get so caught up in the day to day stuff.

Similar exchanges occurred over requests for information related to specific workplace tasks and situations: how to approach new genres, how to get credit or recognition for one's writing, how to dress for the job, whether to walk a picket line or not, how to produce schedule calculations, and how to negotiate salary. Students also responded to each other's requests for specialized technical writing knowledge, on such specifics as impression lines, IT jargon, single sourcing, and the meanings of acronyms.

\section{- Web Forum Instructor Support}

In the web forum, the course instructor also responds to students' problems, sometimes offering explicit advice. For example, in response to a student's concern that she was being stereotyped into doing basic receptionist duties and was not admitted access to bonafide writing tasks, the instructor offered an interpretation of the student's situation and advised a proactive approach:

(16) The ... Club is a small office, and people will likely be expected to do a variety of things, from the grand to the apparently 
menial. I wouldn't get too bent out of shape over one or two instances of "typecasting" work; . . . . Recommendations are *if you're not getting enough writing/editing/design work, take it upon yourself to identify some opportunities (for example, phone conversations with club members are good opps to get a handle on what their info needs are - so this may not just be "answering the phone")* ... .

In another web exchange, the instructor advises a student, whose boss has given her vague instructions, to be "more persistent" and to take some initiative. The editor has told the student: "About the company, just make them sound like the second coming of Christ and you'll do fine." The instructor advises as follows:

(17) I think you need to be more persistent with this editor, That's lazy, vague advice about the "second coming". You need more from him. Get your hands on back issues ... Otherwise ... I think you're being set up for failure here. Don't let it happen.

This kind of instruction meets the criteria Freedman (1994) sets out as necessary for explicit instruction to foster implicit learning: the instructor's practitioner background (as editor, writer, and publisher) enables her to provide accurate information; she is in close proximity to the student's engagement with authentic work, and the student is at an appropriate, proximal level of development to be able to act on this advice (p. 204). As Tuomi-Grohn and Engestrom recommend, the presence of multiple cognitionspractitioner, instructor, student-in an intentional learning situation can alter the dynamics of learning at problematic junctures and foster developmental transfer.

\section{- Collaboration}

Interestingly, off-site students were much less likely to use the web forum, falling back instead on their own resourcefulness. In their off-site "third space," they collaborated and adapted boundary objects opportunistically. Fortuitously, in two cases, two work experience students were assigned to each employer (more commonly students are on their own), so that collaboration was an available recourse and a model for working together that they had learned on other projects. One pair reported that working together helped keep them "on the same page" and structure their work time into "work days." One partner also reported that "writing . . . with a partner . . . tested our writing skills, confidence, and trust in each other's decisions." The second pair of students worked as readers of submitted manuscripts for a magazine. One student explained how they learned from each other through the document cycling of comment sheets:

(18) While rejecting pieces was initially difficult, by the time I was acting as a second reader ... it was almost too easy. Reading [the partner's] criticisms made it easier for me to be harsh in my own comments on a piece.

The student's partner commented similarly: "By reading [the partner's] comments I could quickly obtain a feel for the piece." 
The collaborative pairs of students seemed to make more productive use of shared boundary objects, such as the comment sheets provided by one employer, and an evolving text draft that became an object of feedback from both the employer and others, eventually becoming a published educational text the employer had set as a project task. In both cases, employers, students, and other outsiders collaborated through feedback in their use of these boundary objects, which became important tools for learning and teaching.

\section{- Mentors and Friends}

Off-site students also adopted strategies for actively seeking help and feedback from people outside the employer organization, including a school teacher, a local author, family members, and school peers. One student working alone found the work experience instructor very helpful, as well as peers and mentors who provided information and feedback about "industry practices and culture." Significantly, four students met face-to-face as much with the work experience course instructor as with the employer, communicating directly with the instructor, instead of using the web forum.

\section{- Virtual Sleuthing}

One rare web positing by an off-site student reveals his diminished contextual resources, but also his strategic use of the "track changes" function and email as productive boundary objects. After reading a number of web forum postings about other students' interactions in organizations, this student responded that, in the absence of a "water-cooler environment," he had honed his ability to use the "track changes" tool as a kind of access device for glimpses of his co-workers' personalities and the culture. In the back region of the web forum, he finds a place to share, make tangible, and validate his own experience of relative isolation:

(19) My main struggle in getting to know the culture of the people l'm working for has been about actually seeing one. ... We all work at home, and generally send one another e-mail or post our work to an online office space. This means that there is absolutely no water-cooler environment-none. And yet ... Personality percolates through in an environment ... electronically. ... . Because we exchange documents with "track changes" active, I sometimes get to see the discussion of a given

phrasing or idea .... Those little boxes also occasionally give me insight into the personalities I'm working with. The changed documents can sometimes be very expressive, and the e-mail often contains discourse that's more than just work-related.

\section{Discussion: The Transitional Learning Community}

The findings reveal a dynamic learning community in the back regions of the work experience arena. There is compelling evidence of developmental learning transfer, of resourceful, skilled and knowledgeable students who are poised to achieve "rhetorical maturity" (Miller, 1980). There is also evidence clearly pointing toward the need for improvements in work experience pedagogy. 
The transitional learning communities for these professional writing students are partially constructed as extra-classroom supports that invite and create the conditions for back region practices. They are also an arena for ad hoc, unstructured learning activity. This "constellation" of back region practices becomes the focus of a new community - a focal point towards which transitional students can orient their learning (Wenger, 1998, p. 255). It is a third space of emerging contingencies, new tools, and diverse cognitions that offer genuine learning opportunities to students. As Wenger (1998) points out, "boundaries are ... places where new practices often start. ... and thus new communities take shape" (p. 255). Wenger compares this "constellation of practices" to a "downtown" that provides a "social focus" to which "the communities involved can orient themselves" (p. 259). Here a constellation of boundary practices can be reified as tools for strategic participation:

The reification of the constellation then becomes a boundary object around which communities can use their imagination to orient their engagement, reflect on what they are doing, and explore new avenues for organizational participation. (p. 259)

The web forum functions as one such orienting object for on-site work experience students, productively bringing students' voices together with the voices of others in problem-solving activities. Such a "network of distributed cognition" is usually more characteristic of workplaces than classrooms, so that the presence of these voices in this transitional space seems well suited and conducive to third space learning activities (Cole \& Engestrom, 1993, pp. 34-37). Here students can consolidate their learning, develop strategies for organizational access and participation, and periodically sediment their learning through self-reflexive awareness of how they are "learning to learn."

The goal of transitional pedagogy is to foster learning that occurs as "a response to the pedagogical intentions of the setting" (Wenger, 1998, pp. 265-266). This space has its own intermediary goals that extend beyond the goals of the classroom (Dias et al., 1999, p. 187). It is conducive to a certain bricolage, bridging school and workplace, but existing beyond those two spaces, and fostering an ever-changing mix of cognitions, tools, knowledge and skills. The design of an effective learning community should provide for a balance between "the production of reificative material" (Wenger, 1998, pp. 265-266), such as recommended models, approaches, and other strategic practices, and scaffolding--like the web forum, employer-student interviews, or telephone meetings - to foster participation.

As noted, off-site work experience students tended not to use the web forum, but instead relied heavily upon each other, the work experience instructor, their supervisors, and outsiders. As the findings suggest, the learning strategies of these students, shaped by their off-site context, could be buttressed with stronger "brokering" opportunities (Wenger, 1998, p.105) by elaborating scaffolding with more structured and frequent instructor meetings, employer-instructor conferences, student pairing, employer mentoring meetings, and telephone consultations.

On the other hand, despite the barriers to learning that off-site work experience students face, the evidence adduced from this small study suggests that some students are simply readier than others for transitional learning. In non-technical terms, they 
seem to have a certain type of personality, resourcefulness, and maturity. These traits were also cited by off-site employers who valued "self-directed" students who do not need "supervision and focusing"; students who could work "with very little direction," "worked very well in tandem with [a partner]," could work "independently." Employers also valued "maturity and a sense of responsibility" and "the ability to say, I can't do it, I need help," which one employer cited as "an extremely important skill." Employers valued off-site students who were "self-disciplined," had "good time-management skills," and were able to "compartmentalize ... their time." Off-site students also pointed to the importance of being proactive with employers and possessing self-confidence:

(20) You have to ask. . . . it is up to the student to express what they want out of the experience.

(21) Only students who have the confidence to work with minimal supervision should be assigned this practicum.

They recommended their work experience placements for future students, provided they had good time-management skills, valued flexibility, and preferred part-time work.

Successful off-site work experience students thus seem to be prepared to work actively to "learn to learn" and make their work experience as productive as possible. Besides learning important skills such as time-management and writing in new genres, they reported learning that was not so tangible yet essential to developmental transfer: what they variously described as "the realities of receiving minimal feedback, the "acceptance of critical feedback," the usefulness of developing "a thick skin," and the ability "to think outside the box." They also commented on the benefits of having an engaged mentor. learning:

One student's comment on minimal feedback is a typical expression of such

(22) [I was] surprised by how little feedback I received. . . I was a bit frustrated at first, but I came to realize that this was likely the norm for a freelance writer.

This student decided that a lack of feedback was not necessarily "bad news" because "editors, etc. are often too busy ...., but once they pick up the phone [they] can be quite friendly and approachable." She learned how to be proactive in seeking feedback-not through the electronic communication that characterized most of her work, but through telephone contact. Valuing critical feedback, instead of responding defensively, is also an important maturational shift that signals significant learning transfer from the constructively framed feedback of the classroom to blunter or minimal workplace feedback. One off-site student described the learning work involved in the process of coming to value such feedback and the product that emerged from the process in terms that indicate an important "consequential transition":

(23) [A published author] had lots to say, and a lot of it was harsh. My initial reaction was a combination of denial, self-righteousness, and disbelief. However, when we took a deep breath and started reading [the author's] comments and listening, we started learning. We sat down and went through everything [the author] said. Some of it resulted in major changes 
and some of it we ignored. In the end, we had to admit that we had a much better story than what we had started with. It was a humbling experience ... that really made me appreciate the value of asking for help from an objective third-party.

Another key dimension of developmental transfer is the awareness of being engaged in an ever-changing process. One pair of students described how they managed change:

(24) We shifted our expectations of the project and of each other as the summer went on but we kept communicating with each other what those expectations were. As a result, I think we ended up making a great team.

In this collaboration, the employer had apparently also been an important facilitator, by "encouraging creativity and growth," as one student put it. "What I had originally thought was going to be a small project ended up being much larger because [the employer] saw our abilities and decided to take advantage of them." Facilitating the learning process with mutual and reciprocal modifications among diverse but collaborating participants (students, employer, outside reviewers) helped create the conditions for developmental learning transfer.

In addition to these examples of developmental transfer, the eight off-site students gave evidence of consequential transfer in various forms: "getting published," "seeing my choices going off to the judge" of a writing contest, "hear[ing] our supervisor . . . say that we'd finally made what [the supervisor] had been trying to get other people to make for years," and "having some of the articles published on the web e-zines with my picture and by-line which resulted in a few good samples for my portfolio."

\section{Conclusion}

Ideally, transitional pedagogy should involve a collaborative, fully committed team of employer-practitioners, instructors, and students (Tuomi-Grohn, Terttu, \& Engestrom, 2003), thereby offering some stability and reassurance to students suddenly engulfed in the ever-changing contexts of transitional learning. Effective transitional pedagogy should attenuate, validate and channel the difficulties of learning in a zone of proximal development. It should coax out difficulties instead of preventing them from arising (as sometimes occurs with classroom constraints). As Anson and Forsberg (1990) suggest in their study of writing interns, "instead of finding ways to avoid the difficulties inherent in [transitional] learning, a writer does well to learn how to embrace these difficulties and make them productive" (p. 223). Strategic transitional scaffolding should be an inducement to such learning by making the emergent "an opportunity" (Wenger, 1998, p. 233) instead of eliminating it. In back regions, away from the pressure of the workplace, the emergent, which can be messy and chaotic, can find productive expression.

Transitional structures, both formal and informal, can become dialogical sites for unfettered, unsanctioned sharing and questioning (Lingard \& Haber, 2002, p. 165), where a transitional self can occupy a bonafide speaking position and be heard and supported. This is where I found the transitional voices of these students-especially in their words of advice to each other: "don't try to be a hot-shot. Remember, you are still a 
student: ask dumb questions and lots of them." I also discovered this voice in their acceptance of a transitional self: "it is unlikely that I will become a 'team member,' but more like a call-up from the minors." Others, who were less comfortable and felt like "poseurs," were able to use the web forum as a debriefing back region where they could comment on their sense of giving a fraudulent performance in the front regions. Like resistant student writers in other studies, who consciously situate themselves at some distance, more or less, from the center of a community (Giltrow, 2005), the transitional writer may choose a transitional identity that suits his or her sense of self. This is a self comfortable with a more or less "peripheral" status in the workplace, yet a self that is also monitoring a shift in identity.

Effective transitional scaffolding should distribute and attenuate the sharing of learning experiences by fostering knowledge as local, cognition as social and distributed, and learning as a collective activity that increases the learner's capacity for authentic participation. These design features are consistent with those critical shifts in theories of learning that Pare (2002) has summarized in his study of transitional learning. The four key shifts are as follows:

- Away from a view of knowledge as fixed ... toward a view of knowledge as shifting, dynamic, local, and relative.

- Away from an understanding of cognition as mental processes ... toward a conception of cognition as a social, collective ... activity

- Away from a view of learning as the accumulation of discrete skills and contextfree knowledge, toward a view of learning as the gradually increasing ability to participate in socially-situated, collaborative practices.

- Away from the individual as the unit of attention ... toward a focus on collective activity. (p. 61)

We cannot simply conclude that the presence of transitionally-located scaffolding structures, designed to induce activity characteristic of productive learning communities, results in such transformative experiences. Other factors, such as employer involvement, the degree of cognitive readiness and maturity, opportunities for rehearsal and practice, genre experience, and the peculiarities of individual learning styles, are also at work here. However, the findings of this study do show that transitional writing students deploy these transitional resources in creative and productive ways that facilitate their organizational access and participation. It therefore seems reasonable to claim that such pedagogical structures provide a richer learning environment, an additional and bridging "working" community in the back regions, than strictly classroom activities or lucky workplace circumstances, and that they must enhance students' opportunities for participation and organizational membership.

Based on the results of this study and others like that of Wilson et al., I would suggest the following guidelines for developing an effective transitional pedagogy:

1. Include dedicated scaffolding supports in bonafide transitional spaces, in addition to those located in the classroom and the workplace.

2. Design transitional supports to be similar to workplace supports; for example, include many "cognitions" - the individual voices--virtual, real and distal—of employers, students, instructors, alumni, and practitioners. 
3. Create a focus by integrating transitional supports to invite and facilitate a "constellation of practices" or a "downtown" to which transitional writing students can orient themselves as learners.

4. Provide a balance of pedagogical tools and participatory motivations (for example, make available past students reports advising proactive practices that students must then initiate on their own).

5. Design scaffolding structures that build in sociality and collectivity (vs. individuality).

6. Design scaffolding that is directed explicitly towards organizational goals and only implicitly towards classroom learning outcomes.

7. Strengthen workplace-school connections, channeling resources for activities involving both worlds.

These suggestions are only preliminary proposals and need to be tested further and articulated with other program pedagogical goals. For example, it would be productive to investigate how transitionally located scaffolding fits into the "integrated pedagogical framework" of "layered" literacies for technical writing that Cargile Cook (2002) has proposed, some of which seem to be obvious competencies that would be facilitated by transitional scaffolding: rhetorical literacy (the use of organizational culture and schemas (p. 10), social literacy (the ability to work effectively with others within organizational settings (p. 12), and critical literacy (the ability to "contextualize their writing ... and the concerns of all stakeholders, not just the powerful" (p. 16). The amorphous, "messy" quality of back region learning communities seems particular conducive to the goals of Cargile Cook's literacies, which she advises "should be viewed as extremely fluid, complicating technical communication instructional activities and goals rather than simplifying them" (p. 23). Such "complication" would be validated in transitional spaces and would find a home in the "back regions" of learning.

The findings of this study show that work experience students must negotiate barriers to organizational access and that, while they deploy transitional resources in creative and productive ways to facilitate their organizational access and participation, there is compelling evidence they need stronger support. On the other hand, there is also much evidence of students' resourcefulness, their ad hoc, opportunistic strategies, so it would also be important to avoid over-structuring back region learning. Some resources will be pedagogically structured, others will be found. Clearly, there are benefits to scaffolding structures, but to maximize these benefits, transitional pedagogy needs to strengthen the bridging function of back region learning communities with a comprehensive design--to multiply cognitions, structure workplace-school collaborative activities, provide shared resources and boundary-objects, and facilitate self-reflexive consciousness of those moments when tacit learning becomes fore-grounded as learning transfer. 


\section{References}

Anson, C., \& Forsberg, L. (1990). Moving beyond the academic community: Transitional stages in professional writing. Written Communication, 7 (2), 200-231.

Bakhtin, M. (1981). The dialogic imagination. Austin: University of Texas Press.

Beach, K. (2003). Consequential transitions: A developmental view of knowledge propagation through social organizations. In T. Tuomi-Grohn \& Y. Engestrom (Eds.). Between school and work: New perspectives on transfer and boundarycrossing, (pp. 39-62). Amsterdam: Early Pergamon.

Berkenkotter, C., Huckin T., \& Ackermann, J. (1991). Social context and socially constructed texts: The initiation of a graduate student into a writing research community. In C. Bazerman \& J. Paradis (Eds.). Textual dynamics of the professions, (pp. 191-215). Madison: University of Wisconsin Press.

Berkenkotter, C. \& Huckin, T. (1995). Conventions, conversations, and the writer: An apprenticeship tale of a doctoral student. In C. Berkenkotter \& T. Huckin (Eds.). Genre knowledge in disciplinary communication: Cognition/culture/power, (pp. 117-150). Hillsdale, New Jersey: Lawrence Erlbaum Associates.

Blakeslee, A. (2001). Bridging the workplace and the academy: Teaching professional genres through classroom-workplace collaborations. Technical Communication Quarterly, 10 (2), 169-192.

Burnett, R. (1993). Decision-making during the collaborative planning of coauthors. In A. Penrose \& B. Sitko (Eds.). Hearing ourselves think: cognitive research in the college writing classroom, (pp. 126-146). Oxford: Oxford University Press.

Cargile Cook, Kelli. (2002). Layered literacies: A theoretical frame for technical communication pedagogy." Technical Communication Quarterly. 11.1: 5-29.

Cole, M. \& Engestrom, Y. (1993). A cultural-historical approach to distributed cognition." In G. Salomon (Ed.). Distributed cognitions: Psychological and education considerations, (pp. 1-46). Cambridge, Mass.: Cambridge University Press.

Creswell, J.W. (2007). Qualitative inquiry and research design: Choosing among five approaches. Thousand Oaks: Sage Publications.

Dias, P. (2001). A response to Russ Hunt's review of Worlds Apart. Inkshed, 19 (2), 4-7.

Dias, P., Freedman, A., Medway, P., \& Pare, A. (Eds.). (1999). Worlds apart: Acting and writing in academic and workplace contexts. London: 
Lawrence Erlbaum Associates.

Engestrom, Y. (1999). Innovative learning in work teams: Analyzing cycles of knowledge creation in practice. In Y. Engestrom, R. Miettinen, \& R. Punamaki (Eds.) Perspectives on activity theory, (pp. 326-356). Cambridge, UK: Cambridge University Press.

Engestrom, Y. (1995). Innovative organizational learning in medical and legal settings. In L. Martin, K. Nelson, \&E. Tobach (Eds.). Sociocultural psychology: theory and practice of doing and knowing, (pp. 326-356). Cambridge: Cambridge University Press.

Freedman, A., \& Adam, C. (1996). Learning to write professionally: 'Situated learning' and the transition from university to professional discourse. Journal of Business and Technical Communication, 10 (4), 395-427.

Freedman, A., Adam C., \& Smart, G. (1994). Wearing suits to class: Simulating genres and simulations as genre. Written Communication, 11, 192-226.

Freedman, A. (1994). 'Do as I say': The relationship between teaching and learning new genres. In A. Freedman \& P. Medway (Eds.). Genre and the new rhetoric, (pp. 191-210). London: Taylor \& Francis Ltd.

Gee, J. (1996). Social linguistics and literacies: Ideology in discourses. (2 ${ }^{\text {nd }}$ ed). London: Falmer Press.

Giltrow, J. (2005). Legends of the center: system, self, and linguistic consciousness. In C. Bazerman \& D. Russell (Eds.), Writing selves/ writing societies: Research from activity perspectives, (pp. 363-392). Colorado: The WAC Clearing House and Mind, Culture, and Activity. Retrieved from http://wac.colostate.edu/books/selves_societies/giltrow

Giltrow, J., \& Valiquette, M. (1994). Genres and knowledge: Students writing in the disciplines." In A. Freedman \& P. Medway (Eds.). Learning and teaching genre.(pp. 47-62). Portsmouth, NH: Boynton/Cook, Heinemann.

Goffman, E. (1959). Regions and region behaviour. The presentation of self in everyday life, (pp. 106-140). New York: Doubleday Anchor.

Gordon, J. (Spring 2002). Techne and technical communication: Toward a dialogue. Technical Communication Quarterly, 11 (2), 147-164.

Hunt, R. (2001a). Between planets: What's between the worlds of worlds apart. Inkshed, 19, 4-7.

Hunt, R. (2001b). Review of Worlds Apart: Acting and writing in academic and 
workplace contexts. Technostyle, 18 (1), 142-146.

Hudson, R.A. (1980). Sociolinguistics. Cambridge, Mass.: Cambridge University Press.

Kastman Breuch, L. (Spring 2001). The overruled dust mite: Preparing technical communication students to interact with clients. Technical Communication Quarterly, 10 (2), 193-210.

Ketter, J., \& Hunter, J. (2004). Creating a writer's identity on the boundaries of two communities of practice. In C. Bazerman \& D.R. Russell (Eds.). Writing selves/writing societies. Colorado: The WAC Clearing House and Mind, Culture, and Activity. Retrieved from http://wac.colostate.edu/books/ selves_societies/Ketter

Lave, J., \& Wenger, E. (1991). Situated learning: Legitimate peripheral participation. Cambridge, Mass.: Cambridge University Press.

Ledwell-Brown, J. (2000). Organizational cultures as contexts for learning to write. In P.Dias \& A. Pare (Eds.). Transitions: Writing in academic and workplace settings, (pp. 199-222). Cresskill, New Jersey: Hampton Press.

Lingard, L., \& Haber, R. (2002). Learning medical talk: How the apprenticeship complicates current explicit/tacit debates in genre instruction." In R. Coe, L. Lingard, \& T. Teslenko (Eds.). The rhetoric and ideology of genre, pp. 155-170. Cresskill, NJ: Hampton Press.

Lutz, J. (1989). Writers in organizations and how they learn the image: Theory, research, and implications. In C. Matalene (Ed.). Worlds of writing, (pp. 113 -134). NY: Random House.

Miller, S. (1980). Rhetorical maturity: Definition and development. In A. Freedman \& I. Pringle (Eds.). Reinventing the rhetorical tradition, (pp. 119127). Ottawa: The Canadian Council of Teachers of English.

Pare, Anthony. (2002). Keeping writing in its place: A participatory action approach to workplace communication." In B. Mirel \& R. Spilka (Eds.). Reshaping technical communication: New directions and challenges for the $21^{\text {st }}$ century, (pp. 57-73). Mahwah, NJ: Lawrence Erlbaum Associates.

Pare, A. (2000). Writing as a way into social work: Genre sets, Genre systems, and distributed cognition." In P. Dias \& A. Pare (Eds.) Transitions: Writing in academic and workplace settings, (pp. 145-166). Cresskill, New Jersey: Hampton Press.

Smart, G., \& Brown, N. (Fall 2002). Learning transfer or transforming learning?: Student interns reinventing expert writing practices in the workplace. 
Technostyle, 18 (1), 117-141.

Star, S.L., \& Griesemer, J.R. (1989). Institutional ecology, 'translation' and boundary objects. Social Studies of Science, 19 (3), 387-420.

Tuomi-Grohn, T. \& Engestrom, Y.(Eds.) (2003). Between school and work: New perspectives on transfer and boundary-crossing. Amsterdam: Early Pergamon.

Tuomi-Grohn, T., Engestrom, Y., \& Young, M. (2003). From transfer to boundarycrossing between school and work as a tool for developing vocational education: An introduction. In T. Tuomi-Grohn \& Y. Engestrom (Eds.). Between school and work: New perspectives on transfer and boundarycrossing, (pp. 1-18). Amsterdam: Early Pergamon.

Vygotsky, L. (1978). Mind in society. Cambridge, Mass: Harvard University Press.

Wegner, D., \& Nicholson, M. (2006). The growing occupation of professional writing in academic spaces: Combinations of theory and practice. In R. Graves \& $\mathrm{H}$. Graves (Eds.), Writing centres, writing seminars, writing culture: Writing instruction in Anglo-Canadian universities, (pp. 147-174). Victoria, Can.: Inkshed Publications.

Wenger, E. (1998). Communities of practice. Cambridge, Mass: Cambridge University Press.

Wertsch, J. (1991). Voices of the mind. Cambridge, Mass.: Harvard University Press.

Wickliff, G. (1997). Assessing the value of client-based group projects in an introductory technical communication course. Journal of Business and Technical Communication. 11 (2), 170-192.

Wilson, M., et al. (2005). Between 'worlds apart': Situating student work between the academic classroom and workplace. Technostyle.21 (1), 3-45.

\section{Bio}

Diana Wegner teaches in the Print Futures Professional Writing Program and Communications Department at Douglas College, New Westminster, BC. Her research includes ongoing projects at a municipal site, and the study of transitional writers. She has been published in the Journal of Business and Technical Communication, Rhetor, and Technostyle and in edited collections on language and communication. She has done consulting work for industry and government and for a number of years taught writing courses at Simon Fraser University and the University of British Columbia. 
' For a comprehensive description of the professional writing program, see D. Wegner and M. Nicholson (2006), "The Growing Occupation of Professional Writing in Academic Spaces: Combinations of Theory and Practice," in R. Graves \& H. Graves (Eds.) Writing Centres, Writing Seminars, Writing Culture:

Writing Instruction in Anglo-Canadian Universities, Winnipeg: Inkshed Publications, pp. 147-173. 